\title{
Antitumor effect of a copper (II) complex of a coumarin derivative and phenanthroline on lung adenocarcinoma cells and the mechanism of action
}

\author{
TAOFENG ZHU ${ }^{1 *}$, RUHUA CHEN $^{1 *}$, HAO YU ${ }^{2}$, YAN FENG $^{1}$, JIANQIANG CHEN $^{1}$, \\ QIN LU ${ }^{1}$, JING XIE $^{3}$, WEILIANG DING ${ }^{4}$ and TIELIANG MA ${ }^{4}$ \\ ${ }^{1}$ Department of Respiratory Medicine, The Affiliated Yixing Hospital of Jiangsu University, Yixing, Jiangsu 214200; \\ ${ }^{2}$ Department of Respiratory Medicine, The Affiliated People's Hospital of Jiangsu University, Zhenjiang, Jiangsu 212002; \\ ${ }^{3}$ Department of Geriatrics and ${ }^{4}$ Central Laboratory, The Affiliated Yixing Hospital of Jiangsu University, \\ Yixing, Jiangsu 214200, P.R. China
}

Received November 13, 2013; Accepted June 17, 2014

DOI: $10.3892 / \mathrm{mmr} .2014 .2519$

\begin{abstract}
In order to investigate the effect of a copper (II) complexes of a coumarin derivative and phenanthroline (hereinafter referred to as the coumarin-copper drug) on lung adenocarcinoma cells in vivo and in vitro, along with the mechanism of action, LA795 lung adenocarcinoma cells were treated with different concentrations of coumarin-copper drug. An MTT assay was performed to determine the cell proliferation ratio, cell apoptosis was detected by Annexin V/propidium iodide staining with flow cytometric analysis and western blot analysis was employed to evaluate the expression levels of apoptosis-associated proteins. In addition, an LA795 cell xenograft tumor model was established in nude mice, with mice receiving intraperitoneal injection once a week for three weeks of either 2 or $4 \mathrm{mg} / \mathrm{kg}$ in three divided doses coumarin-copper drug, or phosphate-buffered saline. The tumor grow th curves were drawn and the tumor growth inhibition rates were calculated. The apoptotic index of subcutaneously transplanted tumor cells was determined by terminal deoxynucleotidyl-transferase-mediated dUTP nick end-labeling assay. The coumarin-copper drug effectively inhibited the proliferation of LA795 cells in a doseand time-dependent manner, with the half maximal inhibitory concentration equaling $2.0 \mu \mathrm{mol} / 1$. The coumarin-copper drug also significantly induced LA795 cell apoptosis in a time-dependent manner $(\mathrm{P}<0.05)$, which was accompanied by upregulation p35 and B-cell lymphoma-2 (Bcl-2)-associated X protein (Bax),
\end{abstract}

Correspondence to: Dr Tieliang Ma, The Affiliated Yixing Hospital of Jiangsu University, 75 Tongzhenguan Road, Yixing, Jiangsu 214200, P.R. China

E-mail: matieliang@foxmail.com

*Contributed equally

Key words: coumarin-copper drug, lung adenocarcinoma, LA 795, apoptosis and downregulation of Bcl-2. Furthermore, the coumarin-copper drug significantly inhibited the growth of LA795 tumors in a dose dependent manner $(\mathrm{P}<0.05)$, in accordance with the apoptotic index. In conclusion, the coumarin-copper drug may inhibit the proliferation of LA795 cells through the induction of cell apoptosis, which may be associated with the upregulation of p53 and Bax, with concurrent downregulation of Bcl-2.

\section{Introduction}

Lung cancer remains the most common human cancer worldwide. A total of $\sim 80 \%$ lung cancer patients are histologically classified as having non small cell lung cancer (NSCLC) $(1,2)$. Despite great achievements over the past decades in surgery, radiotherapy and chemotherapy, the five-year survival rate of lung cancer in numerous countries has remained $<15 \%$ (3). Chemotherapy remains the main lung cancer treatment and cisplatin is one of the most widely used first-line chemotherapeutic agents for NSCLC treatment (4).

Although cisplatin is extensively employed as an anticancer drug to cure numerous types of cancer, the development of severe side effects and acquired resistance due to prolonged treatment have provoked the consideration of alternatives circumventing drug resistance (5). With this aim, several classes of metal complex drugs have been manufactured using various ligands and metal ions, and the anticancer activity of these agents has been successfully demonstrated in vivo and in vitro (6-11). Copper is well-known as a bioessential element in humans and copper complexes have proved to be promising candidates for the treatment of cancer $(12,13)$. The mechanism for copper (II) complex-mediated cytotoxicity may be associated with the ability of the drugs to bind and cleave DNA. This results in cell cycle arrest or the generation of reactive oxygen species (ROS), which in turn induce cell death or apoptosis $(14,15)$. Coumarin (1,2-benzopyrone) is structurally the least complex member of a class of compounds known as the benzopyrones (16).

Recently, coumarins have been recognized to possess anti-inflammatory, antioxidant, antithrombotic, antiallergic, hepatoprotective, antiviral and anticarcinogenic activities $(17,18)$. 
Coumarin derivatives have been evaluated in the treatment of human immunodeficiency virus, due to the ability to inhibit human immunodeficiency virus integrase $(19,20)$. Interest in metal complexes of coumarin has arisen from the search for novel lead compounds along with the desire to improve the pharmacological profile. For example, certain notable lanthanide complexes of coumarin derivatives, including bis(4-hydroxy-3-coumarinyl) acetic acid (21), the ligand 8,8'-[1,2-ethanediylbis(nitriloethylidyne)]bis[7-hydroxy-4methyl-2H-1-benzopyran-2-one] and coumarin-3-carboxylic acid have been reported (22). Transition metal complexes with coumarin Schiff bases have also been investigated recently (23). In the present study, the effect of a copper (II) complex with a coumarin derivative and phenanthroline (hereinafter referred to as the coumarin-copper drug; Fig. 1) on LA795 lung adenocarcinoma cells in vivo and in vitro was investigated, along with the mechanism of action.

\section{Materials and methods}

Materials. The coumarin-copper drug was obtained from the State Key Laboratory of Applied Organic Chemistry, College of Chemistry and Chemical Engineering, Lanzhou University (Lanzhou, China). The LA795 adenocarcinoma cell line was obtained from the Cell Culture Center of the Basic Institute of Medical Sciences, Peking Union Medical College (Beijing, China). Cell culture reagents were purchased from Gibco-BRL (Carlsbad, CA, USA). Annexin V-fluorescein isothiocyanate (FITC) and propidium iodide (PI) double staining, and terminal deoxynucleotidyl-transferase-mediated dUTP nick end-labeling (TUNEL) assay kits were purchased from Kaiji BioTech (Nanjing, China). MTT and dimethyl sulfoxide (DMSO) were purchased from Sigma-Aldrich (St. Louis, MO, USA). Polyvinylidene fluoride (PVDF) membranes and non-fat dry milk were obtained from Millipore (Billerica, MA, USA). p53, B-cell lymphoma 2 (Bcl-2)-associated X (Bax) and Bcl-2 polyclonal antibodies were obtained from BioVision (Mountain View, CA, USA). $\beta$-actin polyclonal antibody was purchased from Abmart (Shanghai, China). The AP-conjugated anti-mouse IgG (S372B; Promega Corporation, Fitchburg, WI, USA) and AP-conjugated anti-rabbit IgG (S372B; Promega Corporation) antibodies were obtained from Beyotime Biotech. (Nantong, China). The nude mice (18-22 g) were obtained from the Comparative Medicine Center of Yangzhou University (Yangzhou, China). The study was approved by the ethics committee of The Affiliated Yixing Hospital of Jiangsu University (Yixing, China). Female adult mice (18-22 g) were housed under controlled photoperiod conditions (lights on 08:00-20:00) and were supplied with food and tap water ad libitum. All animal studies were conducted in accordance with the Institutional Animal Care and Use Committee of Jiangsu University.

Cell viability assay. The effect of the coumarin-copper drug on the proliferation of LA795 cells was measured by MTT assay. Briefly, LA795 cells were plated at a density of $1 \times 10^{4}$ cells per well in 96-well plates overnight and then treated with different concentrations of coumarin-copper drug after 48 and $72 \mathrm{~h}$. A volume of $20 \mu \mathrm{l}$ MTT solution was added to each well and the cells were cultured for another $4 \mathrm{~h}$ at $37^{\circ} \mathrm{C}$. The medium was completely removed and $100 \mu \mathrm{l}$ DMSO was added to solubilize MTT formazan crystals. The plates were then agitated and the optical density was determined at $570 \mathrm{~nm}$ (A570) using an ELISA plate reader (infinite F50; Tecan, Männedorf, Switzerland). At least three independent experiments were performed.

Quantification of apoptosis by Annexin V and PI double staining. Apoptotic rates were determined by flow cytometry using an Annexin V/PI apoptosis kit. Briefly, LA795 cells were seeded at a density of $1 \times 10^{6}$ cells per well in six-well plates overnight and then treated with 2 or $4 \mu \mathrm{mol} / 1$ coumarin-copper drug for $48 \mathrm{~h}$. A total of $1 \times 10^{6}$ cells were collected by centrifugation and washed twice with cold phosphate-buffered saline (PBS). Annexin V-FITC/PI staining was performed according to the manufacturer's instructions, the cells were analyzed using a FACScan flow cytometer BD Biosciences (San Jose, CA, USA). and data were examined using CellQuest ${ }^{\mathrm{TM}}$ software (BD Biosciences, Franklin Lakes, NJ, USA). At least three independent experiments were performed.

Western blot analysis. A total of $1 \times 10^{6}$ LA795 cells were seeded in six-well plates overnight. The cells were treated with 2 and $4 \mu \mathrm{mol} / 1$ coumarin-copper drug for $48 \mathrm{~h}$. The cells were then washed twice with PBS. The total proteins were solubilized and extracted with lysis buffer (containing $20 \mathrm{mM}$ 4-(2-hydroxyethyl)-1-piperazineethanesulfonic acid (HEPES), $\mathrm{pH} 7.9,20 \%$ glycerol, $200 \mathrm{mM} \mathrm{KCl}, 0.5 \mathrm{mM}$ EDTA, $0.5 \%$ NP40, $0.5 \mathrm{mM}$ dithiothreitol and $1 \%$ protease inhibitor cocktail; all from Sangon, Shanghai, China). Protein concentration was determined by bicinchoninic acid protein assay (Beyotime Biotech.). The samples were separated by SDS-PAGE, transferred to PVDF membranes by electroblotting and probed with antibodies against p53, Bax, Bcl-2 and $\beta$-actin. Membranes were then incubated with horseradish peroxidase-conjugated secondary antibodies at a 1:1,000 dilution and incubated for $2 \mathrm{~h}$ at room temperature. The blots were developed using an enhanced chemiluminescence kit (Beyotime Biotech.).

Tumor growth curve and inhibition rates. The LA795 lung adenocarcinoma cells were cultured in Dulbecco's modified Eagle's medium supplemented with $10 \%$ fetal bovine serum, $2 \mathrm{~mm}$ L-glutamine, $1 \%$ nonessential amino acids, $100 \mu \mathrm{g} / \mathrm{ml}$ penicillin and $100 \mu \mathrm{g} / \mathrm{ml}$ streptomycin (all from Invitrogen Life Technologies), and incubated at $37^{\circ} \mathrm{C}$ under a humidified atmosphere of $95 \%$ air and $5 \% \mathrm{CO}_{2}$. At $90 \%$ confluence, the cells were harvested and resuspended in PBS at $4 \times 10^{6}$ cells $/ \mathrm{ml}$. The tumor-bearing mice model was established by subcutaneous injection of $1 \times 10^{6}$ cells along the left flank back of the mice. After approximately seven days, a tumor (5-10 $\mathrm{mm}$ in diameter) was observed in each mouse. All tumor-bearing mice were randomly divided into three groups (all $n=10)$ : One group was treated with PBS, whereas the other groups were treated with 2 and $4 \mathrm{mg} / \mathrm{kg}$ coumarin-copper drug by intraperitoneal injection once a week for three weeks, in three divided doses.

Once the size of the tumor reached $5-20 \mathrm{~mm}$ in diameter, the short (a) and long (b) diameters of the tumor were measured using a vernier caliper every seven days. The measurement included the skin thickness. The volumes of the tumors for plotting a growth curve were calculated according to the formula $\mathrm{V}=\mathrm{a}^{2} \mathrm{x} \mathrm{b} \times 0.52$. The tumor inhibition rates were calculated as 


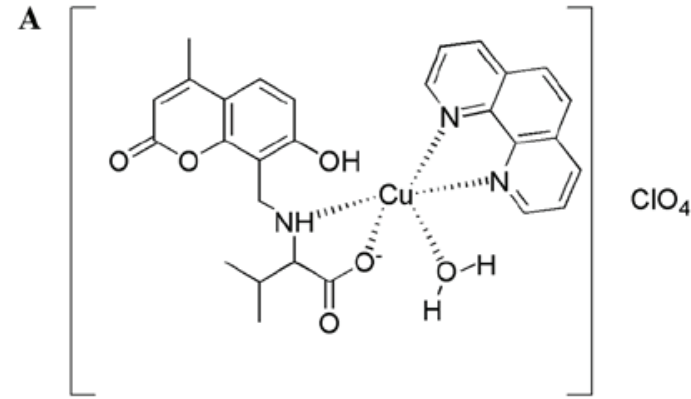

B

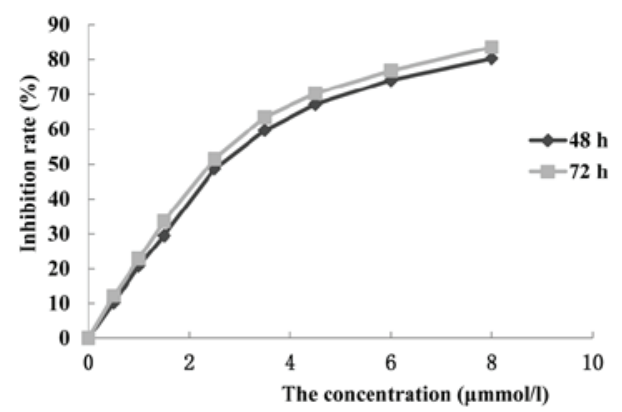

Figure 1. Cytotoxic effect of coumarin-copper drug on LA795 lung adenocarcinoma cells. (A) Chemical structure of coumarin-copper drug. (B) The cells were treated with $0.5,1,1.5,2.5,3.5,4.5,6$ and $8 \mu \mathrm{M}$ coumarin-copper drug for 48 and $72 \mathrm{~h}$, and cell viability was assessed using an MTT assay.

determined by the final measurement of tumor volume according to the following formula: Tumor inhibition rate $=$ (average tumor volume in control group - average tumor volume in treatment group)/mean tumor volume in control group x $100 \%$.

Transplanted tumor apoptosis assay. Transplanted tumor apoptosis was analyzed using the TUNEL assay kit according to the manufacturer's instructions. In brief, All mice were sacrificed by cervical dislocation. The tumor tissues were extracted and $10 \mu$ m-thick frozen sections were prepared and fixed in $4 \%$ formaldehyde (Sangon) for $20 \mathrm{~min}$ at room temperature. This was followed by rinsing with PBS for $30 \mathrm{~min}$ and incubation with $3 \%$ hydrogen peroxide (Sangon) in methanol for $10 \mathrm{~min}$ at room temperature. After washing for $25 \mathrm{~min}$ with PBS, the samples were incubated with $0.1 \%$ Triton X-100 (Sangon) and $0.1 \%$ sodium citrate (Sangon) in water for $30 \mathrm{~min}$ at room temperature. Subsequent to two washes with PBS, pretreated specimens were incubated with $50 \mu$ l terminal deoxynucleotidyl transferase (TdT) labeling reaction buffer at $4^{\circ} \mathrm{C}$ overnight in the dark and then in a humidified atmosphere at $37^{\circ} \mathrm{C}$ for another 2-3 h. For the negative control, TdT was not added to the sample and for the positive control, the cells were treated with DNase I. Subsequently, the slides were incubated with $50 \mu \mathrm{l}$ streptavidin-horseradish peroxidase for $60 \mathrm{~min}$, followed by detection with $50 \mu \mathrm{l}$ diaminobenzidine reagent for $10 \mathrm{~min}$. The sections were observed and images were captured under an optical microscope (Olympus BX41; Olympus, Tokyo, Japan).

Statistical analysis. All data were analyzed by SAS v6.12 software (SAS Institute, Cary, NC, USA) and the results are expressed by mean \pm standard deviation. To compare the differences among multiple groups, statistical significance

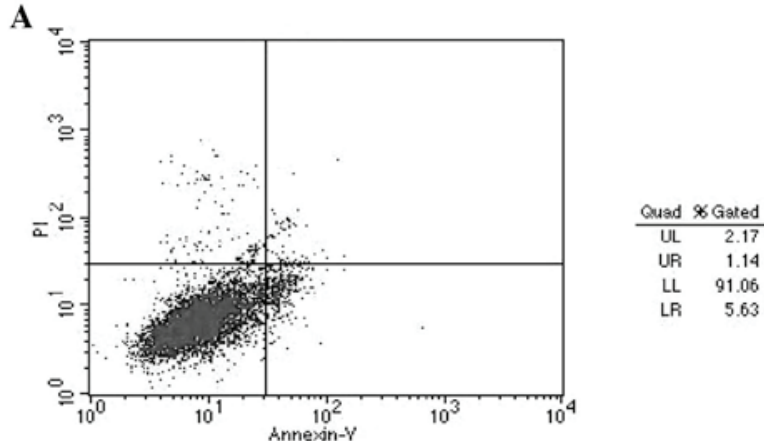

B
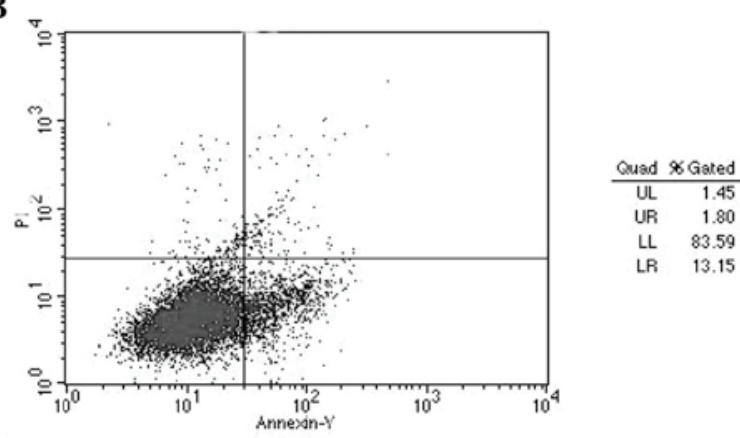

C

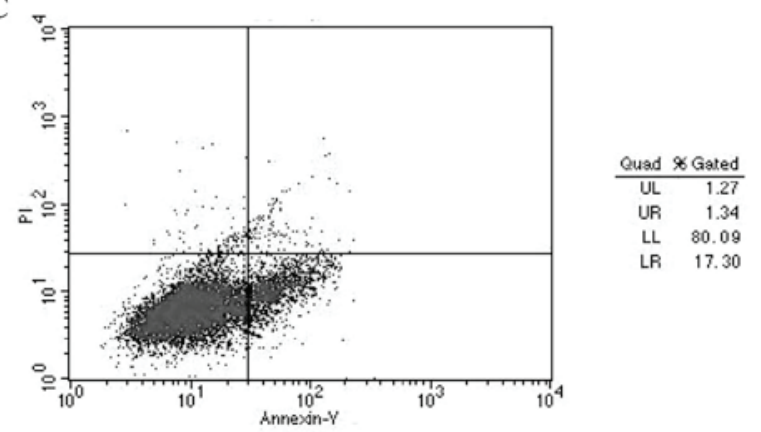

Figure 2. Annexin V-fluorescein isothiocyanate/PI staining detected apoptosis in LA795 lung adenocarcinoma cells following treatment with coumarin-copper drug. (A) Control cells treated with phosphate-buffered saline. (B) Cells treated with $1 \mu \mathrm{g} / \mathrm{ml}$ coumarin-copper drug. (C) Cells treated with $2 \mu \mathrm{g} / \mathrm{ml}$ coumarin-copper drug. $\mathrm{P}<0.05$. PI, propidium iodide; UL, upper left; UR, upper right; LL lower left; LR, lower right.

was analyzed using one-way analysis of variance followed by post-hoc comparisons. $\mathrm{P}<0.05$ was considered to indicate a statistically significant difference.

\section{Results}

Coumarin-copper drug inhibits LA795 cell growth. The viability of cells treated with different concentrations of coumarin-copper drug was determined using an MTT assay. As shown in Fig. 1, the coumarin-copper drug inhibited cell growth in a dose- and time-dependent manner. The half maximal inhibitory concentration of coumarin-copper drug was $2.5 \mu \mathrm{mol} / 1$ after 48 and $72 \mathrm{~h}$ treatment.

Coumarin-copper drug increases the apoptotic rate of LA795 cells. Annexin V/PI staining and flow cytometric measurement were used to quantify the apoptotic percentages in the total LA795 cell population in order to determine the effect of coumarin-copper drug. As shown in Fig. 2, the number of 


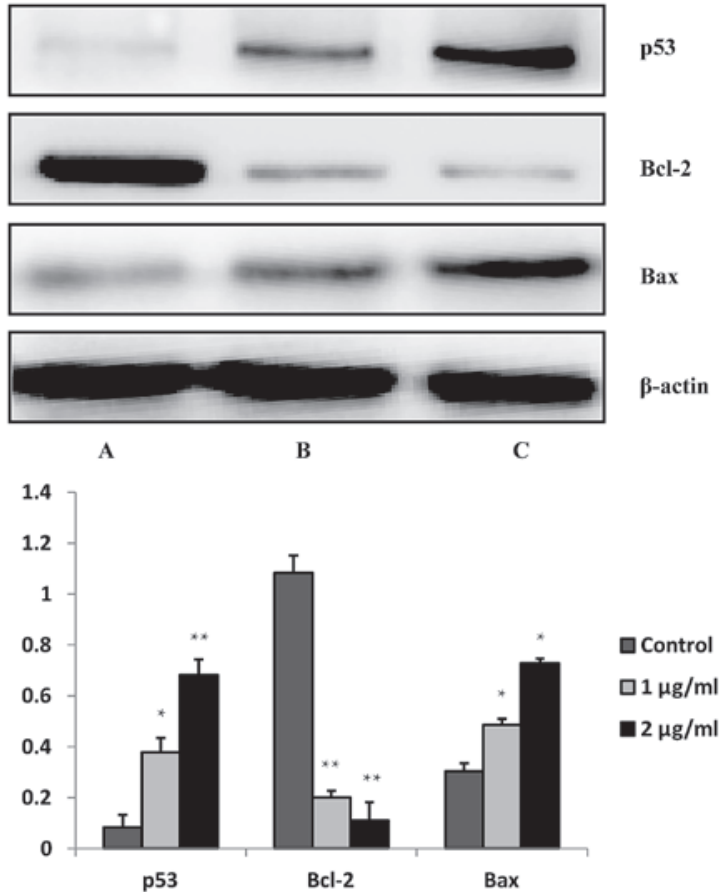

Figure 3. Western blot analysis of expression levels of the p53, Bax, Bcl-2 protein on LA759 lung adenocarcinoma cells following coumarin-copper drug treatment. Lane A, control cells with phosphate-buffered saline treatment; lane B, cells treated with $1 \mu \mathrm{g} / \mathrm{ml}$ coumarin-copper drug; and lane $\mathrm{C}$, cells treated with $2 \mu \mathrm{g} / \mathrm{ml}$ coumarin-copper drug. The values below the figure indicate the changes in protein expression levels of the bands normalized to the expression levels of $\beta$-actin. Bcl-2, B-cell lymphoma 2; Bax, Bcl-2-associated $\mathrm{X}$. ${ }^{\mathrm{P}}<0.05$ and ${ }^{* *} \mathrm{P}<0.01$, compared with control.

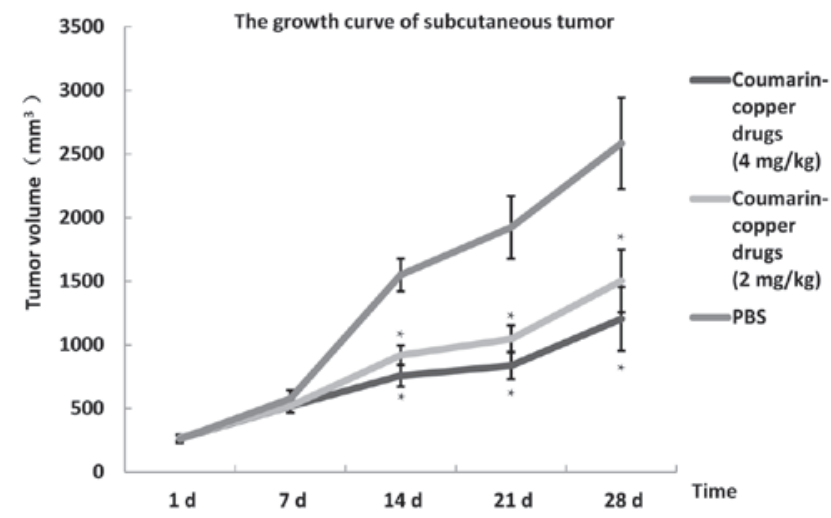

Figure 4. Growth curves of subcutaneous tumors in nude mice. The tumor growth curves indicate significant reductions in tumor volume in the coumarin-copper drug group at days 14,21 and 28 compared with PBS group $(\mathrm{P}<0.05)$. Tumor inhibition rate $=(2,584.32-1,204.86) / 2,584.32 \cdot 100 \%=53.3 \%$. PBS, phosphate-buffered saline.

apoptotic cells increased in a dose-dependent manner following incubation with 1 and $2 \mu \mathrm{g} / \mathrm{ml}$ coumarin-copper drug for $48 \mathrm{~h}$. The percentages of total apoptotic cells were $13.46 \pm 1.34 \%$ and $17.34 \pm 1.68 \%$ in the 1 and $2 \mu \mathrm{g} / \mathrm{ml}$ coumarin-copper treatment groups respectively, whereas in the PBS group, it was only $5.62 \pm 0.85 \%(\mathrm{P}<0.05)$.

Changes in p53, Bax and Bcl-2 protein expression levels in LA795 cells. Apoptosis-associated signaling proteins were detected in order to examine the apoptotic pathway involved

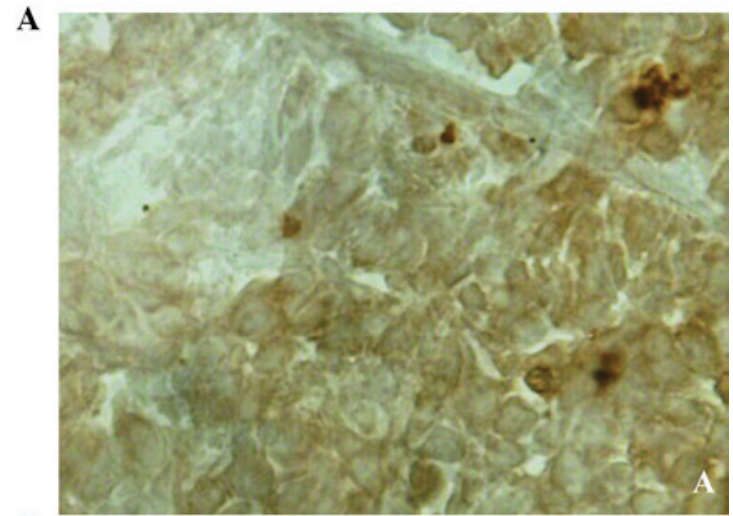

B

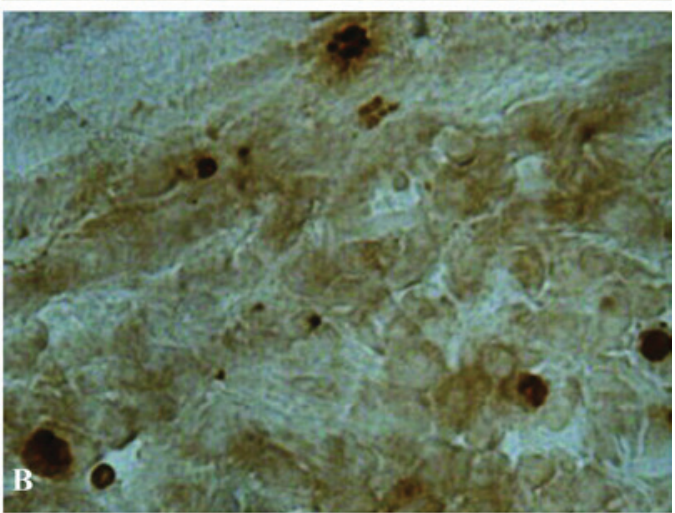

C

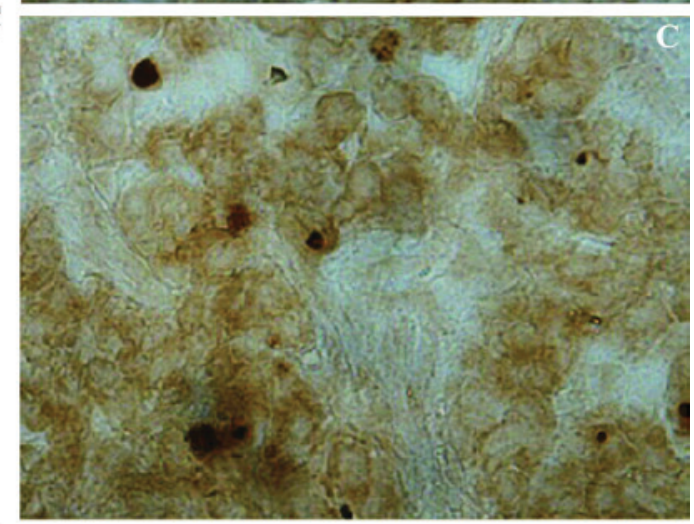

D

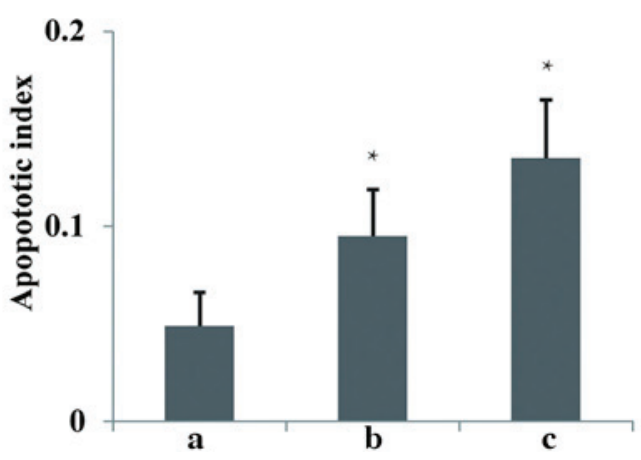

Figure 5. Apoptosis in subcutaneously transplanted tumor cells treated with coumarin-copper drug, as determined by terminal deoxynucleotidyl-transferase-mediated dUTP nick end-labeling assay. (A) Control cells with PBS treatment. (B) LA759 cells treated with $2 \mathrm{mg} / \mathrm{kg}$ coumarin-copper drug. (C) LA759 cells treated with $4 \mathrm{mg} / \mathrm{kg}$ coumarin-copper drug. (D) Apoptotic index of: a, PBS group; b, $2 \mathrm{mg} / \mathrm{kg}$ drug group; and c, $2 \mathrm{mg} / \mathrm{kg}$ drug group $\left({ }^{*} \mathrm{P}<0.05\right)$. PBS, phosphate-buffered saline.

in the LA759 cell response to the coumarin-copper drug treatment. The expression levels of the apoptotic-associated proteins p53 and Bax protein were significantly increased. 
By contrast, Bcl-2 protein expression was markedly downregulated in a dose-dependent manner following incubation with coumarin-copper drug for 48 h (Fig. 3).

Coumarin copper drug inhibits tumor growth in vivo. The mouse tumor growth curves are presented in Fig. 4. The tumor volumes were significantly lower in the coumarin-copper drug treatment groups than in the PBS group $(\mathrm{P}<0.05)$. Of note, the coumarin-copper drug effectively inhibited tumor growth in a dose-dependent manner $(\mathrm{P}<0.05)$. The tumor inhibition rates were calculated as determined by the final measurement of tumor volume and according to the formula described above.

Coumarin copper drug causes apoptosis of tumor cells in vivo. The TUNEL method was used to assess apoptosis in the tumor cells. As expected, the number of apoptotic cells and the apoptotic index were significantly increased in the coumarin-copper drug groups as compared with the PBS group $(\mathrm{P}<0.05)$. Therefore, the coumarin-copper drug effectively induced apoptosis in a dose-dependent manner $(\mathrm{P}<0.05$; Fig. 5).

\section{Discussion}

Various transition metal complexes with coumarin Schiff bases have been assessed for their anti-cancer activity, and certain complexes have been found to inhibit the proliferation of PC3 prostate cancer cells $(23,24)$. In the present study, a coumarin-copper drug was found to inhibit the proliferation of LA795 lung adenocarcinoma cells in a concentration- and time-dependent manner. To determine whether the reduction in LA795 cell growth was attributable to the induction of apoptosis in cancer cells, Annexin V/PI and TUNEL assays were employed to detect apoptotic cells. The assays revealed that the number of apoptotic cells increased in a dose-dependent manner. Coumarin-copper drug also inhibited LA795 cell tumor growth in mice in a dose-dependent manner. Smaller visible cancer nodules were identified on the surface of the mice following treatment with coumarin-copper drug, compared with the control treatment, with an inhibition rate of 53.3\%.

The upregulation of p53 and Bax by the coumarin-copper drug may have been involved in the induction of apoptosis in cancer cells. Normal p53 is crucial in inducing apoptosis and cell cycle checkpoints in human and murine cells following DNA damage (25). This conclusion has been further supported by the finding that p53 is the most commonly mutated tumor suppressor gene (26). The p53 protein is important in cell cycle control and the induction of apoptosis during the treatment period in cancer patients (27). Furthermore, the sensitivity of cancer cells to chemotherapeutic agents is greatly influenced when the function of p53 is abrogated (28). Bax transcription is activated by $\mathrm{p} 53$, inducing apoptosis resulting from DNA damage. Apoptosis is modulated by antiapoptotic and proapoptotic effectors, which involves a large number of proteins. The proapoptotic and antiapoptotic members of the Bcl-2 family regulate programmed cell death and are targets of anticancer therapy (29). The ratio of cell death antagonists (Bcl-2, Bcl-2 extra large protein) to cell death agonists (Bax, Bcl-2 extra small protein, Bcl-2-associated death promoter, Bcl-2 homology 3 interacting domain death agonist) determines whether a cell responds to an apoptotic stimulus. The proapoptotic Bcl-2 family protein Bax and the antiapoptotic protein Bcl-2 are important in the regulation of apoptosis (30). When Bcl-2 is produced in excess, cells are protected from Bax-induced apoptosis. Conversely, when Bax expression levels are high, the cells proceed to apoptosis. Therefore, the ratio between $\mathrm{Bcl}-2$ and Bax determines whether cells undergo apoptosis. In the present study, the coumarin-copper drug downregulated $\mathrm{Bcl}-2$ protein expression while simultaneously upregulating Bax protein expression. These results indicated that the coumarin-copper drug induced p53 protein expression in LA795 cells. The basic mechanisms of inhibition were due to cytotoxic and cell apoptosis effects. These results may improve the understanding of the pharmacological mechanism of coumarin-copper drug in cancer treatment.

At present, cisplatin is the most effective chemotherapeutic agent in the treatment of NSCLC. However, the use of cisplatin is limited due to severe side effects, such as anemia, neurotoxicity and nephrotoxicity, and the development of drug resistance $(31,32)$. Therefore, there is an urgent requirement for the development of novel, efficacious drugs to treat lung cancer. In conclusion, the findings of the present study demonstrated that coumarin-copper drug exhibited potent antitumor activity against LA795 cancer cells by inducing apoptosis in vitro and in vivo. Therefore, the coumarin-copper drug possesses the potential for development as an agent for lung cancer therapy. Further experiments are required to analyze the effect of coumarin-copper drug administered in combination with other antitumor compounds.

\section{Acknowledgements}

This study was supported in part by the Development Fund of Clinical Science and Technology, Jiangsu University (grant no. JLY20120072, 2012).

\section{References}

1. Parkin DM, Bray F, Ferlay J and Pisani P: Global cancer statistics, 2002. CA Cancer J Clin 55: 74-108, 2005.

2. Jemal A, Thun MJ, Ward EE, et al: Mortality from leading causes by education and race in the United States, 2001. Am J Prev Med 34: 1-8, 2008

3. Erridge SC, Møller H, Price A and Brewster D: International comparisons of survival from lung cancer: pitfalls and warnings. Nat Clin Pract Oncol 4: 570-577, 2007.

4. Schiller JH, Harrington D, Belani CP, et al; Eastern Cooperative Oncology Group: Comparison of four chemotherapy regimens for advanced non-small-cell lung cancer. N Engl J Med 346: 92-98, 2002.

5. Kim HK, Choi IJ, Kim CG, et al: A gene expression signature of acquired chemoresistance to cisplatin and fluorouracil combination chemotherapy in gastric cancer patients. PLoS One 6: e16694, 2011.

6. Zhang CX and Lippard SJ: New metal complexes as potential therapeutics. Curr Opin Chem Biol 7: 481-489, 2003.

7. van Rijt SH and Sadler PJ: Current applications and future potential for bioinorganic chemistry in the development of anticancer drugs. Drug Discov Today 14: 1089-1097, 2009.

8. Gasser G, Ott I and Metzler-Nolte N: Organometallic anticancer compounds. J Med Chem 54: 3-25, 2011.

9. Sanghamitra NJ, Phatak P, Das S, Samuelson AG and Somasundaram K: Mechanism of cytotoxicity of copper (I) complexes of 1,2-bis(diphenylphosphino)ethane. J Med Chem 48: 977-985, 2005.

10. Seelig MH, Berger MR and Keppler BK: Antineoplastic activity of three ruthenium derivatives against chemically induced colorectal carcinoma in rats. J Cancer Res Clin Oncol 118: 195-200, 1992 
11. Dyson PJ and Sava G: Metal-based antitumour drugs in the post genomic era. Dalton Trans 1929-1933, 2006.

12. Marzano C, Pellei M,Tisato F and Santini C: Copper complexes as anticancer agents. Anticancer Agents Med Chem 9: 185-211, 2009.

13. Chaviara AT, Christidis PC, Papageorgiou A, et al: In vivo anticancer, anti-inflammatory, and toxicity studies of mixed-ligand $\mathrm{Cu}(\mathrm{II})$ complexes of dien and its Schiff dibases with heterocyclic aldehydes and 2-amino-2-thiazoline. Crystal structure of $[\mathrm{Cu}(\mathrm{dien})(\mathrm{Br})(2 \mathrm{a}-2 \mathrm{tzn})](\mathrm{Br})(\mathrm{H}(2) \mathrm{O})]$. J Inorg Biochem 99: 2102-2109, 2005.

14. Jamieson ER and Lippard SJ: Structure, Recognition, and Processing of Cisplatin-DNA Adducts. Chem Rev 99: 2467-2498, 1999.

15. Tardito S, Bussolati O, Maffini M, et al: Thioamido coordination in a thioxo-1,2,4-triazole copper(II) complex enhances nonapoptotic programmed cell death associated with copper accumulation and oxidative stress in human cancer cells. J Med Chem 50: 1916-1924, 2007.

16. Egan D, O'Kennedy R, Moran E, et al: The pharmacology, metabolism, analysis, and applications of coumarin and coumarin-related compounds. Drug Metab Rev 22: 503-529, 1990

17. Pochet L, Doucet C, Schynts M, et al: Esters and amides of 6-(chloromethyl)-2-oxo-2H-1-benzopyran-3-carboxylic acid as inhibitors of alpha-chymotrypsin: significance of the 'aromatic' nature of the novel ester-type coumarin for strong inhibitory activity. J Med Chem 39: 2579-2585, 1996.

18. Kostova I, Raleva S, Genova P and Argirova R: Structure-Activity Relationships of Synthetic Coumarins as HIV-1 Inhibitors. Bioinorg Chem Appl 2006: 68274, 2006.

19. Kirkiacharian S, Thuy DT, Sicsic S, et al: Structure-activity relationships of some 3-substituted-4-hydroxycoumarins as HIV-1 protease inhibitors. Farmaco 57: 703-708, 2002.

20. Yu D, Suzuki M, Xie L, Morris-Natschke SL and Lee KH: Recent progress in the development of coumarin derivatives as potent anti-HIV agents. Med Res Rev 23: 322-345, 2003.
21. Deng WR, Wu JG and Long LS: Lanthanide complexes of di(4-hydroxycoumarinyl-3)-acetic acid and their anticoagulant action. Bul Soc Chim Belg 101: 439-443, 1992.

22. Dobson AJ and Gerkin RE: Coumarin-3-carboxylic acid. Acta Crystallogr C 52: 3081-3083, 1996.

23. Bagihalli GB, Avaji PG, Patil SA and Badami PS: Synthesis, spectral characterization, in vitro antibacterial, antifungal and cytotoxic activities of $\mathrm{Co}(\mathrm{II}), \mathrm{Ni}(\mathrm{II})$ and $\mathrm{Cu}(\mathrm{II})$ complexes with 1,2,4-triazole Schiff bases. Eur J Med Chem 43: 2639-2649, 2008 .

24. Jia L, Xu XM, Xu J, et al: Synthesis, characterization, cytotoxic activities, and DNA-binding studies of ternary copper(II) complexes with new coumarin derivatives. Chem Pharm Bull (Tokyo) 58: 1003-1008, 2010.

25. May P and May E: Twenty years of p53 research: structural and functional aspects of the p53 protein. Oncogene 18: 7621-7636, 1999.

26. Cheah PL and Looi LM: p53: an overview of over two decades of study. Malays J Pathol 23: 9-16, 2001.

27. Friesen C, Herr I, Krammer PH and Debatin KM: Involvement of the CD95 (APO-1/FAS) receptor/ligand system in drug-induced apoptosis in leukemia cells. Nat Med 2: 574-577, 1996.

28. Brown JM and Wouters BG: Apoptosis, p53, and tumor cell sensitivity to anticancer agents. Cancer Res 59: 1391-1399, 1999.

29. Goodsell DS: The molecular perspective: Bcl-2 and apoptosis. Stem Cells 20: 355-356, 2002.

30. Cory S and Adams JM: The Bcl2 family: regulators of the cellular life-or-death switch. Nat Rev Cancer 2: 647-656, 2002.

31. Douillard JY, Eckardt J and Scagliotti GV: Challenging the platinum combinations in the chemotherapy of NSCLC. Lung Cancer 38 (Suppl 4): 21-28, 2002.

32. Stewart DJ: Mechanisms of resistance to cisplatin and carboplatin. Crit Rev Oncol Hematol 63: 12-31, 2007. 